\title{
Design for Simulation System of the Aviation Autopilot
}

\author{
Yin Sai Guo ${ }^{1, a^{*}}$, Yi Zhang ${ }^{1, b}$, Ming Ke Cheng ${ }^{1}$,Wei $\mathrm{Wu}^{1, \mathrm{e}}$ \\ 'Department of graduate, Xijing University, Xi'an710123, China; \\ a*guoysxj@163.com, bzhangyjd@163.com,
}

Keywords: Aviation autopilot; Simulation system; Inclined channel; Course channel; Pitch channel.

\begin{abstract}
A simulation system of the aviation autopilot for teaching and training is established. By analyzing the function, structure and principle of the aviation autopilot, the aviation autopilot simulation system is established to realize the real-time control of flight environment. The simulation system mainly refers to the real-time control of the steady status and manipulation status in the inclined channel, course channel and pitch channel. The system has the following characteristics: convenient operation, stable work, convenient observation.
\end{abstract}

\section{Introduction}

The purpose of the aviation autopilot: stabilize the plane pitching angle, inclined angle and course angle; keep the given pressure level of the aircraft; control the rise, decline and turn of the aircraft; change a flat to make it fly into the flat in any state; automatic control elevator adjustment and constantly lift elevator surface under load[1] [2]. The aviation autopilot the following characteristics: the aircraft will have not any adjustment; autopilot is on by turning on the button in any state [3].

\section{Working Principle}

Autopilot consists of three relatively independent channels, namely: the inclined channel, course channel and pitch channel [4]. The inclined channel controls aileron; the course channel controls elevator; the pitch channel controls rudder. Working principle of each channel is shown in figure 1. The manipulation components are not directly effect on the channel. Sensitive element: measure the aircraft state and motion parameters (angle, angular velocity, height, etc.) and convert them into the electrical signals which are proportional to the parameters. Manipulation components: electrical signals controlling the aircraft are generated by the artificial manipulation. Server: The rudder surface is deflect to a angle by the server (a power plant). The rudder angle is proportional to electrical signals controlled by the sensitive components and manipulation components.

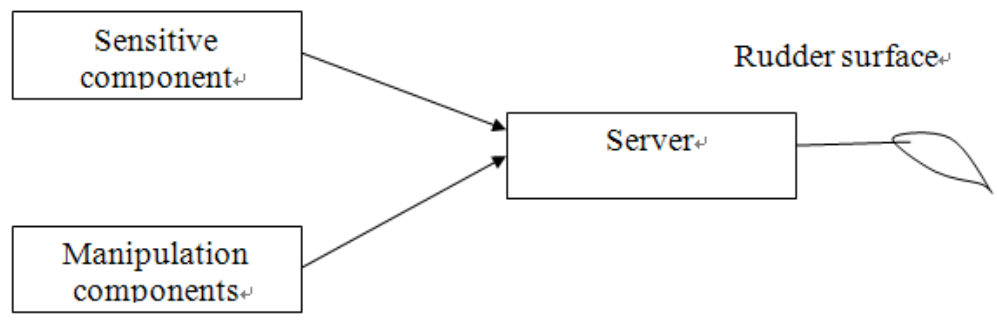

Fig. 1 Working principle of the aviation autopilot 


\section{Design for simulation system of the aviation autopilot}

The inclined channel. Working principle of the inclined channel is shown in figure 2.

Angular transducer: measure slant angle $\gamma$ of the aircraft which is translated into the proportional electrical signal [5]. Directional gyroscope: measure heading error Angle $\Delta \Phi$ of the aircraft which is translated into the proportional electrical signal. Angular velocity transducer: measure slant angular velocity $\dot{\gamma}$ of the aircraft which is translated into the proportional electrical signal.

The steady status. The control equations of steady status

$\delta=\mathrm{k}_{\dot{\gamma}} \dot{\gamma}+\mathrm{k}_{\gamma}+\mathrm{k}_{\Phi} \Delta \Phi$

In the formula: $\mathrm{k}_{\dot{\gamma}}$-The slant angular transmission ratio

$\mathrm{k}_{\gamma^{-}}$The slant angular velocity transmission ratio

$\mathrm{k}_{\Phi^{-}}$The heading angle $\Phi$ transmission ratio

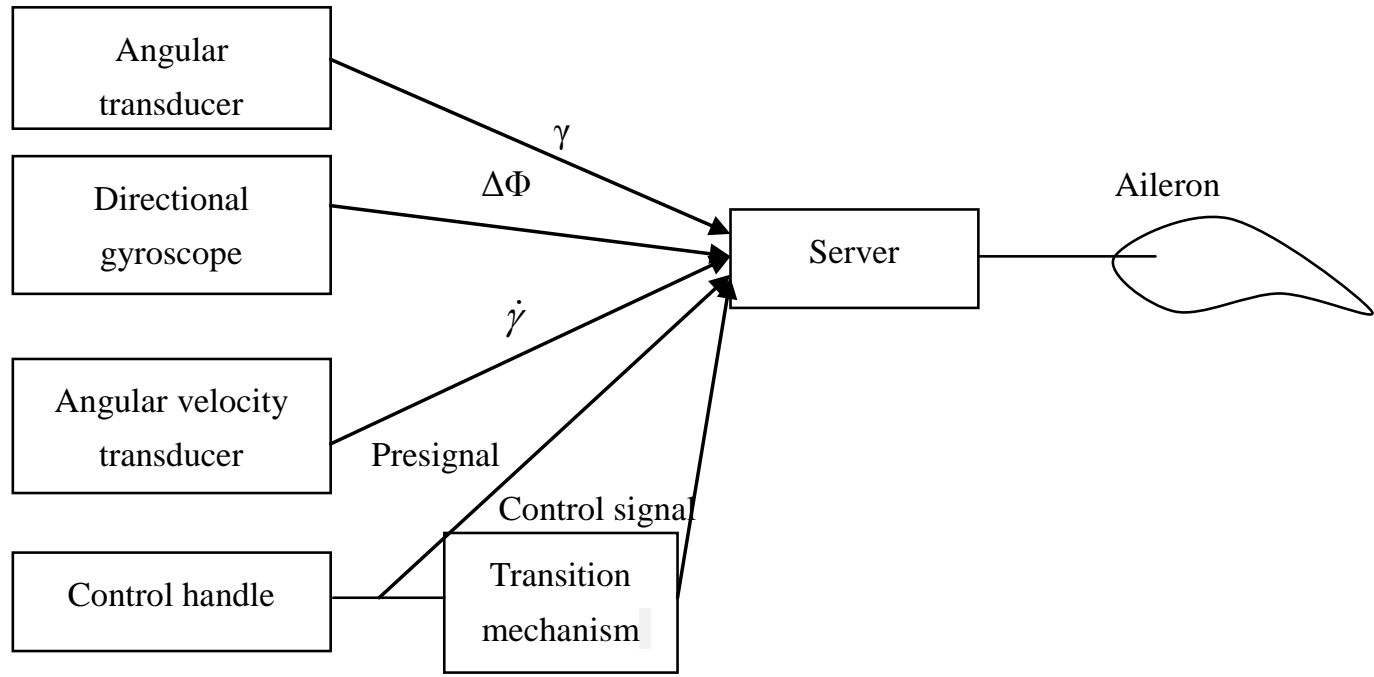

Fig. 2 Working principle of the inclined channel

When the aircraft flew in a stable state, affected by factors such as wind or uneven engine thrust and the aircraft, it will deviate from the original stable state and produce a tilt angle $\gamma$. The sensor will measure the corresponding the slant angle, the slant angular velocity and the heading error angle.

The control equations:

$\delta \uparrow=\mathrm{k}_{\gamma} \uparrow+\mathrm{k}_{\gamma} \gamma \uparrow+\mathrm{k}_{\Phi} \Delta \Phi \uparrow$

After the aileron rudder deflection, the aircraft under the action of the actuator torque restores to the original steady state.

The control equations:

$\delta \downarrow=\mathrm{k}_{\gamma} \downarrow+\mathrm{k}_{\gamma} \quad \dot{\gamma} \quad \downarrow+\mathrm{k}_{\Phi} \Delta \Phi \downarrow$

Until the both sides of the equation are zero and the aircraft restores to the original state of stable, the stable process is the end. 
The manipulation status. The control equations of manipulation status:

$\delta=\mathrm{K}_{\gamma}\left(\mathrm{r}-\gamma_{\mathrm{g}}\right)+\mathrm{k}_{\gamma} \gamma$

In the formula: $\gamma_{\mathrm{g}}$-the deflection angle

The aircraft flight state is changed by deflecting control handle an angle [6] [7]. The potentiometer is drove by controlling the motor of transition mechanism of the box, to output control signal. The size of the control signal is a linear relationship with time. Its slope is proportional to the deflection displacement of control handle.

The course channel . Working principle of the course channel is shown in figure 3.

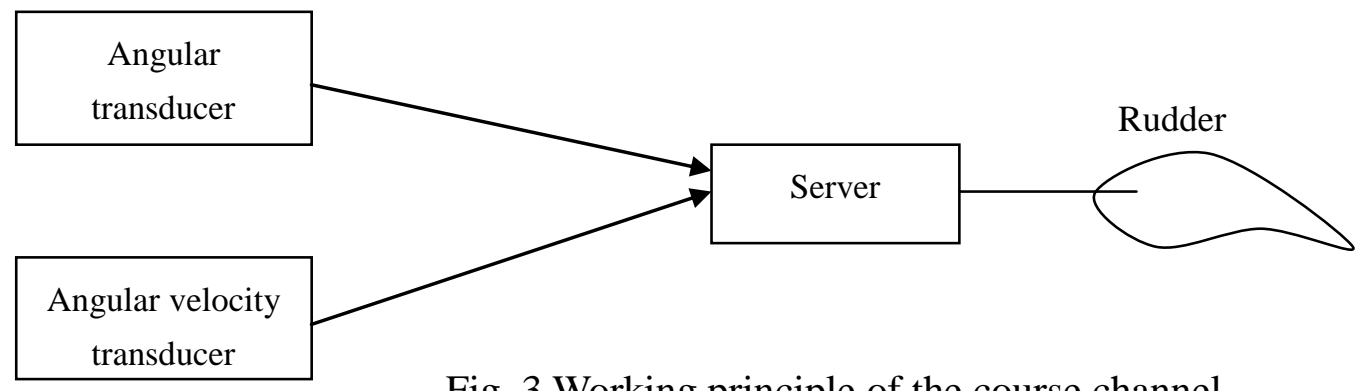

Fig. 3 Working principle of the course channel

The course error signal or manipulate control signal is only imposed on aileron channel. Roll signal $\gamma$ generated by aileron channel is introduced on course channel. This aileron channel controls the velocity vector. Course channel control head tracking speed vector coordinate deflection, so as to complete the course stability and control.

The steady status. The control equations of steady status

$\delta_{\mathrm{y}}=\mathrm{k}_{\dot{\phi}} \dot{\phi}+\mathrm{k}_{\mathrm{y}} \gamma$

$\delta_{\mathrm{x}}=\mathrm{k}_{\mathrm{r}} \mathrm{r}+\mathrm{k}_{\dot{\gamma}} \dot{\gamma}+\mathrm{k}_{\Phi} \Delta \Phi$

When the aircraft works in yaw direction under the action of lateral force, the course deviation signal $\Delta \Phi$ is introduced on the inclined channel, leading to the aileron out, which makes the velocity vector partial back[8] [9]. At the same time the slant angular signal $\mathrm{r}$ is imposed on the course channel to offset reverse modification rudder angle generated by the part of the speed gyro. The slant angular of the plane is proportional to the yaw angle. The rest of angle and yaw moment is to ensure angle and velocity of the head return to the original steady state.

The manipulation status. The control equations of manipulation status

$\delta_{\mathrm{y}}=\mathrm{k}_{\dot{\phi}} \dot{\phi}+\mathrm{k}_{\mathrm{y}} \gamma$

$\delta_{\mathrm{z}}=\mathrm{K}_{\gamma}\left(\mathrm{r}-\gamma_{\mathrm{g}}\right)+\mathrm{k}_{\dot{\gamma}} \dot{\gamma}$

The velocity vector deflection depends on tilt control signal in the manipulation status [10] [11]. The main signal of the head deflection is from the slant angle $r$ of the course channels. It must overcome the partial stable steering torque and yaw damping torque generated by speed gyro, so as to drive the head tracking speed vector coordinate zero sideslip angle.

The pitch channel. Working principle of the pitch channel is shown in figure 4.

The steady status. The control equations of steady status

$\delta_{\mathrm{Z}}=\mathrm{k}_{\mathrm{v}} \mathrm{V}+\mathrm{k}_{\dot{V}} \dot{V}+\mathrm{k}_{\mathrm{rv} \gamma}+\mathrm{K}_{\mathrm{h}} \Delta \mathrm{H}+\mathrm{K}_{\dot{H}} \dot{H}$

The manipulation status. The control equations of manipulation status

$\delta=\mathrm{kv}\left(\mathrm{v}-\mathrm{v}_{\mathrm{g}}\right)+\mathrm{k}_{\dot{V}} \dot{V}$

Its pitch stable and manipulation process are similar to the inclined channel. 


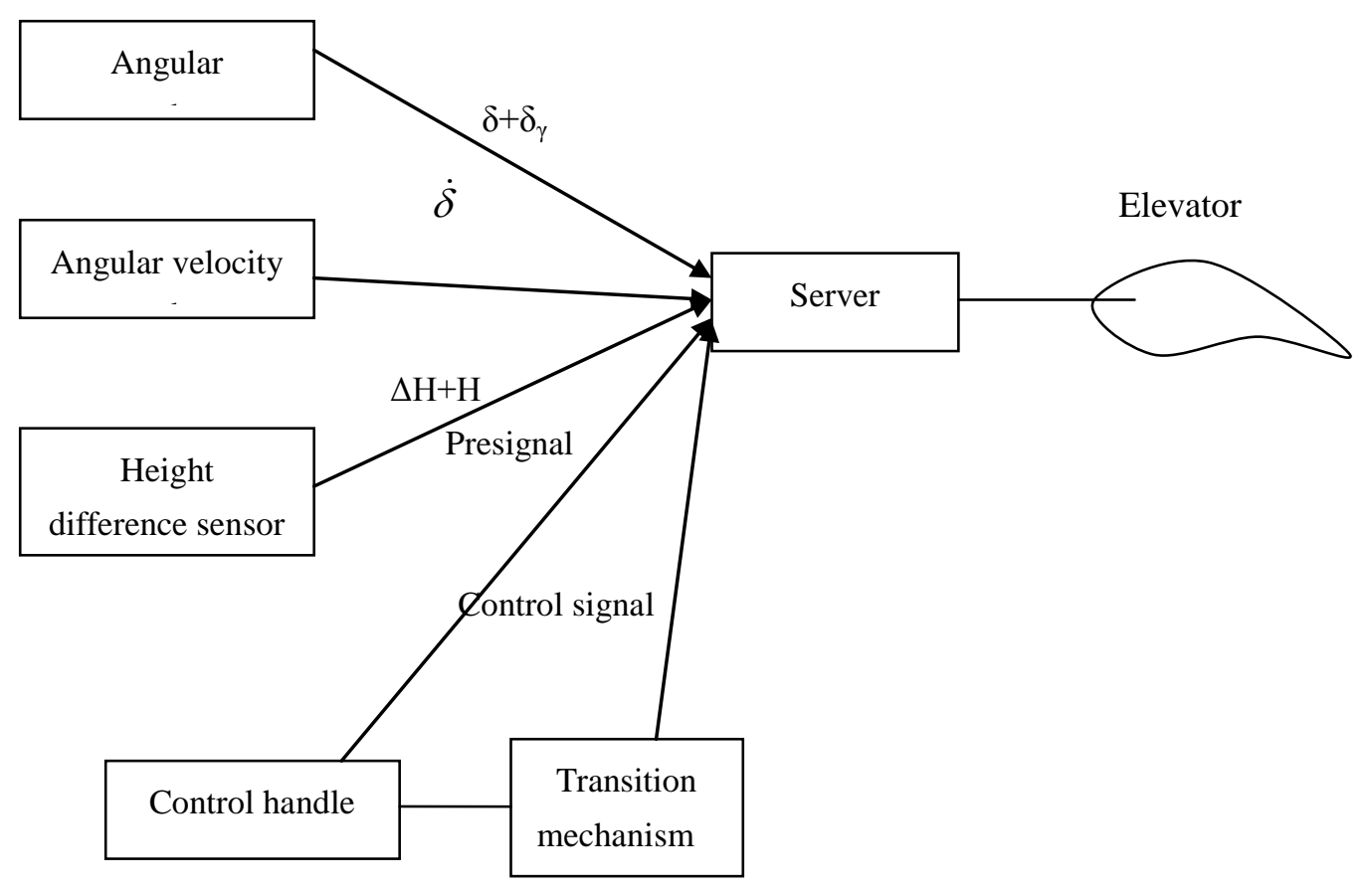

Fig. 4 Working principle of the pitch channel

\section{Summary}

A simulation system of the aviation autopilot for teaching and training is established. Autopilot consisting of three relatively independent channels (the inclined channel, course channel and pitch channel) is designed to meet the simulated flight of the aviation autopilot in the steady status and manipulation status.

\section{Acknowledgements}

This work was supported by the Natural Science Foundation of Shaanxi Province (Program No. 2013JM8040), the Scientific Research Program Funded by Shaanxi Provincial Education Department (Program No. 2013JK1204) and Graduate Student Innovation Fund of Xijing University.

\section{References}

[1]Harris D B B \& H C, Jr. Automation in General Aviation: Two Studies of Pilot Responses to Autopilot Malfunctions[J]. The International Journal of Aviation Psychology, 2009, 9(2):155-174.

[2]Broussard J R, Downing D R, Bryant W H. Design and flight testing of a digital optimal control general aviation autopilot $\hat{\Sigma}[\mathrm{J}]$. Automatica, 1985, 21(1):23-34.

[3]Benoff D. Autopilot Training Modules[J]. Business \& Commercial Aviation, 2003.

[4]Parasuraman R. Effects of Manual and Autopilot Control on Mental Workload and Vigilance During Simulated General Aviation Flight[J]. Transportation Human Factors, 2010, 1(2):187-200.

[5]Gati B. Open source autopilot for academic research - The Paparazzi system[C]. //American Control Conference (ACC), 2013. IEEE, 2013:1478 - 1481.

[6]Ming-jiang L. Design and application of the simulation experiment for cabin pressurization 
system in civil aviation aircraft[J]. Laboratory Science, 2010.

[7]Wen-ming R, Jiang-hua Z, Sheng W. Design of Hardware In the Loop Simulation Platform for Mini Airship Autopilot[J]. Computer Engineering, 2011.

[8]Jin L, Zhao-dong H. A Research on the Simulation Approach Based on System Dynamics for Aviation Equipment's Cost of Repairing Maintenance[J]. Aircraft Design, 2014.

[9]Shengyi Y, Kunqin L, Jiao S. Design And Simulation Of The Longitudinal Autopilot Of Uav Based On Self-Adaptive Fuzzy Pid Control[J]. Computational Intelligence \& Security .cis.international Conference on, 2009:634 - 638.

[10]Tong-shuan L. Computer Simulation System of Three-axis Turntable Based on RTW and RTX[J]. Aviation Precision Manufacturing Technology, 2012.

[11]Touat M A, Tunik A A. Design of uav robust autopilot based on adaptive neuro-fuzzy inference system[J]. Proceedings of National Aviation University, 2012, (4). 